\title{
Retrospective views of psychiatric in-patients regaining mental capacity
}

\author{
Gareth S. Owen, Anthony S. David, Peter Hayward, Genevra Richardson, George Szmukler
} and Matthew Hotopf

\section{Background}

An individual's right to self-determination in treatment decisions is a central principle of modern medical ethics and law, and is upheld except under conditions of mental incapacity. When doctors, particularly psychiatrists, override the treatment wishes of individuals, they risk conflicting with this principle. Few data are available on the views of people regaining capacity who had their treatment wishes overridden.

\section{Aims}

To investigate individuals' views on treatment decisions after they had regained capacity.

\section{Method}

One hundred and fifteen people who lacked capacity to make treatment decisions were recruited from a sample of consecutively admitted patients to a large psychiatric hospital. After 1 month of treatment we asked the individuals for their views on the surrogate treatment decisions they received.

\section{Results}

Eighty-three per cent (95\% Cl 66-93) of people who regained capacity gave retrospective approval. Approval was no different between those admitted informally or involuntarily using Mental Health Act powers $\left(\chi^{2}=1.52, P=0.47\right)$. Individuals were more likely to give retrospective approval if they regained capacity $\left(\chi^{2}=14.2, P=0.001\right)$.

\section{Conclusions}

Most people who regain capacity following psychiatric treatment indicate retrospective approval. This is the case even if initial treatment wishes are overridden. These findings moderate concerns both about surrogate decision-making by psychiatrists and advance decision-making by people with mental illness.

\section{Declaration of interest}

None.
Modern medical ethics gives great weight to the patient's right of self-determination in treatment decisions. ${ }^{1}$ This principle of 'autonomy' has been gaining prominence alongside the older medical ethical principles of 'nonmaleficence' and 'beneficence' but its full nature and implications remain unclear - especially in psychiatric settings. ${ }^{2}$ Medical law seeks to safeguard autonomy through the framework of informed consent and the related concepts of mental capacity (or competence) and best interests. Mental capacity has, accordingly, acquired a central place in modern medical law. Within the doctrine of informed consent it is a prerequisite for valid treatment consent or refusal: the principle the law uses to test whether an individual's treatment choice must be respected as autonomous.

What happens when autonomy is lost and treatment can only be given by overriding the expressed wishes of the individual? Typically the law will bifurcate into frameworks based on incapacity/best interests and frameworks based on mental disorder/risk. In England and Wales, for example, this distinction has recently been enshrined in two statutes: the Mental Capacity Act and the Mental Health Act. Both permit, with conditions, forms of involuntary treatment and both apply to mental disorder broadly defined. Similar dual frameworks of law - one providing substitute decision-making when capacity is lost and one applying risk (or dangerousness) management procedures to those with mental disorder whether with or without capacity - exist in many other developed legal systems. ${ }^{3}$

Stone called the human rights approach to involuntary treatment the 'thank you theory of paternalistic intervention' ${ }^{4}$ because it is based on the premise that overriding an individual's refusal of treatment is justified only if that refusal lacks capacity and the treatment is likely to benefit the person. ${ }^{5}$ The implication is that the person would 'thank' the treating doctor later if and when capacity is regained.

The ethical stakes are high when it comes to involuntary treatment and the issues are at their most stark in psychiatry although they are not limited to psychiatry. Previous studies have sought to investigate the rationale for involuntary treatment in psychiatric settings by measuring the proportion of individuals who change their views about treatment after receiving it involuntarily under law. ${ }^{6,7}$ But for changes of view to have moral significance we need to know whether they constitute autonomous expressions. The fact that views have changed in the direction of agreeing with the treating doctor, does not, by itself, tell us this. A recent UK study ${ }^{8}$ has addressed the views of a large number of psychiatric in-patients about whether an involuntary admission for treatment 1 year ago was justified. Only $40 \%$ thought it was but the capacity to make treatment decisions at the time these views were expressed was unknown.

Mental capacity, as a legal test of autonomous decisionmaking, provides a frame for interpreting the moral significance of wishes about treatment. To our knowledge, no studies have investigated individuals' views on such treatment decisions after they had regained capacity. Hence we carried out a follow-up study in which we determined the presence or absence of capacity to make treatment decisions on admission to hospital and we then sought the participants' views 1 month later, after having established whether or not capacity had been regained. We have formed a large case series of people's views following decisional incapacity deriving from a sample of 350 consecutive admissions to an urban psychiatric hospital. Our aims were to report the retrospective views on the surrogate decision-making individuals received on admission when lacking capacity: whether it was 
required and whether it was of the right kind. Of particular interest were the views of individuals who were treated involuntarily on admission when lacking capacity and then regained capacity.

\section{Method}

Between February 2006 and June 2007, consecutively admitted in-patients to three general adult psychiatric wards (serving a deprived inner-city area) at the Maudsley Hospital, London, were included in this cohort study. The study was approved by the local research ethics committee. Full details are given elsewhere. ${ }^{9}$ At the time of the study, individuals were either admitted involuntarily using the powers of the Mental Health Act 1983 or 'informally' where these powers were not invoked. Neither the Mental Capacity Act 2005 nor the Deprivation of Liberty Safeguards 2008 had yet come into force. The main criteria for the use of the Mental Health Act are: the 'nature or degree' of the mental disorder; the health or safety of the individual, or the protection of others; and absence of an alternative means of providing treatment. Treatment refusal, although not a criterion for detention under the Mental Health Act, strongly associates with the use of these powers. ${ }^{3}$

\section{Participants}

Participants were identified by regular examination of electronic medical records and consultations with ward nursing staff. The sole exclusions were individuals from other catchment areas or transfers from other in-patient facilities.

Potential participants were approached for a research interview. Those assenting were given full details of the study. Written consent was sought. The interview was stopped if there was any subsequent change in choice or resistance. Individuals were offered $\mathfrak{k} 5$ for their time. Capacity assessments were held as close to admission as possible.

If individuals were found to lack capacity at admission they were followed up. The follow-up assessment took place at either the point of discharge from hospital or at 1 month (whichever was sooner). We chose 1 month because this was the average length of stay for people admitted to the Maudsley Hospital acute wards at the time of the study. At follow-up the capacity assessment was repeated and participants were asked about their views on surrogate treatment decision-making. The permission procedure was the same. Figure 1 shows the flow of individuals through the study.

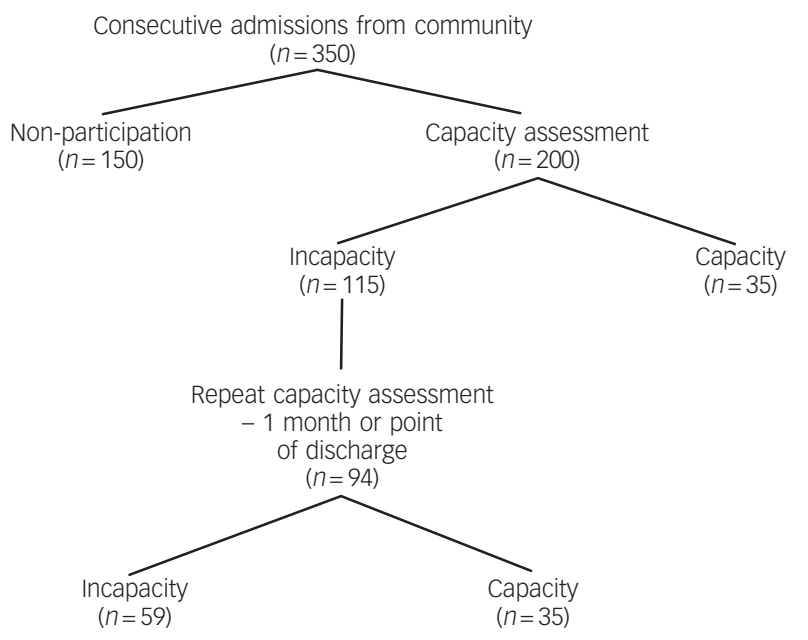

Fig. 1 Flow of participants through the study.

\section{Assessment of capacity}

Relevant information about the participant's presenting problems, ICD-10 diagnosis ${ }^{10}$ and treatment plan was obtained from the medical record. The interviewer (G.S.O.) clarified whether the main treatment decision was stabilisation on medication or admission to hospital for a place of safety/assessment. If it was medication, the capacity assessment centred on the decision to take the prescribed medication or not. If it was hospitalisation, it was the capacity to decide whether to be in hospital or not. Follow-up capacity assessments related to the main treatment decision at admission.

The capacity judgement was based on a clinical assessment (notes, review and clinical interview) and the administration of the MacArthur Competence Assessment Tool for Treatment (MacCAT-T). ${ }^{11,12}$ Previous studies have demonstrated excellent interrater reliability $(\kappa>0.8)$ when the MacCAT-T is used to guide a clinical judgement. ${ }^{13,14}$ The MacCAT-T is a semistructured interview that provides relevant information disclosures to the individual about their illness, the nature of treatment options and their risks and benefits. The assessor evaluates capacity in terms of four abilities relating to the disclosures: understanding, appreciation, reasoning and expressing a choice. These abilities have evolved in reflection of the case law in the USA. They also reflect the requirements of the Mental Capacity Act 2005 in English law. A key feature of the capacity test is that it requires evidence that the decision-making process is impaired rather than the decision-making outcome.

\section{Assessment of participant's views on surrogate decision-making}

All participants who were followed up were asked for their views on the surrogate decisions they received following admission and about surrogate treatment decision-making in general. Participants were asked to think back to their admission and were asked: 'do you think the right decisions were taken on your behalf?'. Responses were recorded as yes, no or don't know. We also asked participants to respond to four statements on a fivepoint scale ranging from 'strongly agree' to 'strongly disagree' to allow for degrees of belief. Two questions were asked in positive and negative frames. The first addressed the need for surrogate decision-making at admission ('I feel doctors decided when I had the ability to decide myself' and 'I feel doctors decided for me when I needed them to') and the second addressed whether the surrogate decision-making was of the right kind ('I think doctors made decisions I wish they had not made' and 'I think the decisions that the doctors made where the right ones for me').

Views relating to surrogate decision-making in general were elicited by asking participants for their views on who should make treatment decisions if they were not able and whether doctors should be able to make decisions on behalf of some people with mental health problems. Answers were summarised.

\section{Analysis}

Participant characteristics, proportions of individuals with capacity and their views on surrogate decision-making are presented descriptively. Simple statistical comparisons were made.

\section{Results}

Details of the 350 consecutive admissions are given elsewhere. ${ }^{9}$ In total, 200 individuals were interviewed on admission and 115 lacked capacity to make the principal treatment decision. From this sample of 115 people, $94(82 \%)$ were re-interviewed at the 


\begin{tabular}{|c|c|c|c|c|c|}
\hline \multirow[b]{2}{*}{ Statement regarding the admission } & \multicolumn{5}{|c|}{$n(\%)$} \\
\hline & Strongly agree & Agree & Neither agree nor disagree & Disagree & Strongly disagree \\
\hline $\begin{array}{l}\text { I feel doctors decided when I had the ability to decide } \\
\text { for myself }\end{array}$ & $2(10)$ & $2(10)$ & $4(20)$ & $7(35)$ & $5(25)$ \\
\hline I feel doctors decided for me when I needed them to & $7(33)$ & $12(57)$ & $1(5)$ & $1(5)$ & 0 \\
\hline I think doctors made decisions I wish they had not made & $1(5)$ & $3(15)$ & $2(10)$ & $9(45)$ & $5(25)$ \\
\hline $\begin{array}{l}\text { I think the decisions that the doctors made were the } \\
\text { right ones for me }\end{array}$ & $8(38)$ & $9(43)$ & $2(10)$ & $1(5)$ & $1(5)$ \\
\hline
\end{tabular}

\begin{tabular}{|c|c|}
\hline Question & $n$ \\
\hline \multicolumn{2}{|c|}{$\begin{array}{l}\text { If you were not able to make decisions, who should make } \\
\text { them for you? }\end{array}$} \\
\hline Professionals & 14 \\
\hline Family members & 9 \\
\hline Supernatural (e.g. God) & 1 \\
\hline No one & 1 \\
\hline Unsure & 0 \\
\hline \multicolumn{2}{|c|}{$\begin{array}{l}\text { Do you think that doctors should be able to make decisions on } \\
\text { behalf of some people who have mental health problems? }\end{array}$} \\
\hline Unqualified yes & 15 \\
\hline Qualified yes & 5 \\
\hline No & 1 \\
\hline Unsure & 0 \\
\hline
\end{tabular}

point of discharge or 1 month later (whichever was sooner). The median time was 27 days (interquartile range 22-30). Overall, 21 participants (18\%) were lost to follow-up (10 refused reassessment and 11 were discharged before being seen and were noncontactable). Table DS1 shows the characteristics of participants on admission and at follow-up.

Of those followed up, 35 people (37\%) regained capacity to make the principal treatment decision. Of these 35 individuals, 29 (83\%; 95\% CI 66-93) answered yes to the question 'were the right decisions taken on your behalf?. This retrospective endorsement did not differ according to whether individuals were admitted informally or under the Mental Health Act $\left(\chi^{2}=1.52\right.$, $P=0.47)$. People were more likely to give this retrospective endorsement if they regained capacity $\left(\chi^{2}=142, P=0.001\right)$.

Tables 1-4 show the views on surrogate decision-making in people regaining capacity in more detail. Tables 1 and 2 shows the views of people who were treated involuntarily under the Mental Health Act on admission, and Tables 3 and 4 show the views of people who were treated informally on admission.
Fifty-nine $(63 \%)$ of the participants who were followed up did not regain capacity. Forty-nine of these people were able to give an answer to the question 'were the right decisions taken on your behalf?. Twenty (41\%; 95\% CI 27-56) answered yes to that question. This retrospective endorsement did not differ according to whether participants were admitted informally or under the Mental Health Act $\left(\chi^{2}=0.75, P=0.69\right)$. More detailed views on surrogate decision-making in this group are shown in Tables 5-7, although problems with participants understanding and answering the questions led to incomplete data - particularly in Table 7.

\section{Discussion}

\section{Main findings}

Doctors, particularly psychiatrists, as part of their practice, sometimes override the treatment wishes of their patients. We know that mental incapacity is common in both in-patient psychiatric and medical settings ${ }^{9,15}$ and we are beginning to clarify how it relates to clinical concepts such as diagnosis and insight. ${ }^{16}$ There are virtually no data on the overriding of treatment wishes and few on the effects of clinical improvement ${ }^{6,7,17}$ despite the obvious importance of the matter in clinical practice. In this area, doctors may feel precariously balanced between liabilities for negligence on the one hand and assault on the other. Because of the high ethical premium placed on self-determination, acts of overriding treatment wishes stand out and call for justification. We studied what people think when they are on the receiving end of such acts.

The majority of individuals who regained decisional capacity (80-90\%) indicated that they thought they needed surrogate decision-making by doctors during their recent admission and that it was of the right kind. Between 5 and 20 per cent indicated that they thought it was not needed or not of the right kind. Most people regaining decisional capacity stated that doctors or family should make decisions if they were unable. Almost all participants said that doctors should be able to make decisions on behalf of some people who have mental health problems.

There were no clear differences in the views expressed about surrogate decision-making between those who were treated

Tables 3 Attitudes to admission of participants who regained capacity and were admitted informally $(n=14)$

\begin{tabular}{|c|c|c|c|c|c|}
\hline \multirow[b]{2}{*}{ Statement regarding the admission } & \multicolumn{5}{|c|}{$n(\%)$} \\
\hline & Strongly agree & Agree & Neither agree nor disagree & Disagree & Strongly disagree \\
\hline $\begin{array}{l}\text { I feel doctors decided when I had the ability to decide } \\
\text { for myself }\end{array}$ & 0 & $1(7)$ & $1(7)$ & $5(36)$ & $7(50)$ \\
\hline I feel doctors decided for me when I needed them to & $9(64)$ & $4(29)$ & 0 & $1(7)$ & 0 \\
\hline I think doctors made decisions I wish they had not made & $1(7)$ & 0 & 0 & $6(43)$ & $7(50)$ \\
\hline $\begin{array}{l}\text { I think the decisions that the doctors made were the } \\
\text { right ones for me }\end{array}$ & $9(64)$ & $3(21)$ & $1(7)$ & 0 & $1(7)$ \\
\hline
\end{tabular}




\begin{tabular}{|c|c|}
\hline Question & $n$ \\
\hline \multicolumn{2}{|c|}{$\begin{array}{l}\text { If you were not able to make decisions, who should make } \\
\text { them for you? }{ }^{a}\end{array}$} \\
\hline Professionals & 7 \\
\hline Family members & 10 \\
\hline Supernatural (e.g. God) & 0 \\
\hline No one & 0 \\
\hline Unsure & 0 \\
\hline \multicolumn{2}{|c|}{$\begin{array}{l}\text { Do you think that doctors should be able to make decisions } \\
\text { on behalf of some people who have mental health problems? }\end{array}$} \\
\hline Unqualified yes & 9 \\
\hline Qualified yes & 5 \\
\hline No & 0 \\
\hline Unsure & 0 \\
\hline
\end{tabular}

involuntarily under the Mental Health Act on admission compared with those who were treated informally. In Kane et al's 1983 study in the USA, ${ }^{7} 69 \%$ of patients who were judged by their doctor to be $80 \%$ improved said they thought it fortunate they were detained when asked about it 2 months later. Our study suggests that when regaining capacity rather than clinical improvement is used as the outcome variable, the levels of endorsement of surrogate decision may be higher.

The views of people who did not regain capacity were more mixed. Fifty-nine per cent did not give retrospective endorsement of the decisions that were made on their behalf. Many of them thought professionals or family members should be able to make surrogate decisions but there were also views that only God should be able to make surrogate decisions or that no one should make surrogate decisions. Although these views on surrogate treatment decisions have to be interpreted in the context of present incapacity, clinicians need to have regard to them when planning future treatment. These individuals' relative lack of endorsement of the treatment might have had some justification - after all, the treatment had not led to their regaining capacity over approximately 1 month - but firm conclusions cannot be drawn here. Information after longer follow-up would be valuable particularly in light of the results from Priebe et $a l^{8}$ mentioned above.

\section{Limitations}

This study has limitations. It is a series drawn from consecutive admissions to psychiatric in-patient units within a single UK urban district with results that may not generalise to other in-patient settings. Further, consideration needs to be given to the face validity of the hindsight views we elicited. A range of contextual factors may influence the expressions of hindsight approval. Thus, participants who expressed approval might have felt that 'saying the right thing' would shorten their stay in hospital. In contrast, others who did not give hindsight approval might have found it difficult to reverse strongly held and expressed differences of opinions with the treating team during the acute phase of an admission. Further, the manner in which treatment decisions were overridden, which may be reflected in the strength of ongoing therapeutic alliance, may be important in influencing the views expressed by participants. We tried to minimise these contextual factors by emphasising the researcher's independence from the clinical team and giving assurances that the interview would not affect the treating team's decisions. Capacity assessments were made prior to eliciting views on surrogate decision-making in order to reduce observer bias in the capacity assessment. We used both positively and negatively framed questions to elicit retrospective views.

\section{Implications}

Most participants who regained capacity agreed with the surrogate decision-making that had taken place during their admission to hospital. They may not have much liked the process of admission or the services received - there may be no 'thank you' - but they indicated approval nonetheless. This was the case even in people whose treatment wishes were overridden by doctors using the powers of the Mental Health Act. This implies that most individuals when regaining capacity (where consents or refusals

\begin{tabular}{|c|c|c|c|c|c|}
\hline \multirow[b]{2}{*}{ Statement regarding the admission } & \multicolumn{5}{|c|}{$n(\%)$} \\
\hline & Strongly agree & Agree & Neither agree nor disagree & Disagree & Strongly disagree \\
\hline $\begin{array}{l}\text { I feel doctors decided when I had the ability to decide } \\
\text { for myself }\end{array}$ & $15(48)$ & $6(19)$ & $6(19)$ & $3(10)$ & $1(3)$ \\
\hline I feel doctors decided for me when I needed them to & $4(13)$ & $10(32)$ & $5(16)$ & $3(10)$ & $9(29)$ \\
\hline I think doctors made decisions I wish they had not made & $15(47)$ & $4(13)$ & $6(19)$ & $4(13)$ & $3(10)$ \\
\hline $\begin{array}{l}\text { I think the decisions that the doctors made were the } \\
\text { right ones for me }\end{array}$ & $2(6)$ & $10(32)$ & $5(16)$ & $5(16)$ & $9(29)$ \\
\hline
\end{tabular}

Tables 6 Attitudes to the admission of participants who did not regain capacity and who were admitted informally $(n=23)$

\begin{tabular}{|c|c|c|c|c|c|}
\hline \multirow[b]{2}{*}{ Statement regarding the admission } & \multicolumn{5}{|c|}{$n(\%)$} \\
\hline & Strongly agree & Agree & Neither agree nor disagree & Disagree & Strongly disagree \\
\hline $\begin{array}{l}\text { I feel doctors decided when I had the ability to decide } \\
\text { for myself }\end{array}$ & $5(28)$ & $5(28)$ & $4(22)$ & $2(11)$ & $2(11)$ \\
\hline I feel doctors decided for me when I needed them to & $2(11)$ & $8(42)$ & $1(5)$ & $2(11)$ & $6(32)$ \\
\hline I think doctors made decisions I wish they had not made & $7(37)$ & $2(11)$ & $3(16)$ & $4(21)$ & $3(16)$ \\
\hline $\begin{array}{l}\text { I think the decisions that the doctors made were the } \\
\text { right ones for me }\end{array}$ & $2(11)$ & $7(37)$ & $3(16)$ & $1(5)$ & $6(32)$ \\
\hline
\end{tabular}




\begin{tabular}{lr} 
Table 7 Attitudes to surrogate decision-making in general \\
in participants who did not regain capacity $(n=59)$ & $n$ \\
Question & \\
If you were not able to make decisions, who should make $^{\text {them for you? }}{ }^{\text {P }}$ & 12 \\
Professionals $_{\text {Family members }}$ & 13 \\
Supernatural (e.g. God) & 5 \\
No one & 6 \\
Unsure & 1 \\
\hline $\begin{array}{l}\text { Do you think that doctors should be able to make decisions } \\
\text { on behalf of some people who have mental health problems? }\end{array}$ & 11 \\
Unqualified yes & 10 \\
Qualified yes & 10 \\
No & 2 \\
Unsure & \\
a. Some participants expressed views for more than one category. & \\
\hline
\end{tabular}

carry legal respect - whether wise or unwise) retrospectively judge their incapable states of mind to have required surrogate decisionmaking. If this can be taken to indicate that most people with mental illness who regain capacity would use their past experience to make anticipatory decisions about treatment that would favourably acknowledge the potential role for surrogate decision-making then it might assuage some of the concerns surrounding the use of psychiatric advance directives, at least when they are drafted following the experience of acute illness. There is some evidence that psychiatric crisis planning resembling advance directives reduces compulsive treatment. ${ }^{18}$

Psychiatry is under an obligation to reflect upon practices that cause the public concern. Overriding the treatment wishes of individuals is one such practice. This study contributes some empirical data to help this reflection. We think it contributes a moderate degree of reassurance both concerning surrogate decision-making by psychiatrists and advance decision-making by people with mental illness.

Gareth S. Owen, MRCPsych, Department of Psychological Medicine and Psychiatry, Institute of Psychiatry; Anthony S. David, FRCPsych, Department of Psychological Medicine and Psychiatry, Institute of Psychiatry; Peter Hayward, PhD, Department of Psychology, Institute of Psychiatry; Genevra Richardson, LLM, School of Law, King's College London; George Szmukler, FRCPsych, Health Services Research Department, Institute of Psychiatry; Matthew Hotopf, PhD, MRCPsych, Department of Psychological Medicine and Psychiatry, Institute of Psychiatry, London, UK

Correspondence: Gareth S. Owen, Department of Psychological Medicine, Institute of Psychiatry, Weston Education Centre, Cutcombe Road, London SE5 9RS, UK. Email: g.owen@iop.kcl.ac.uk

First received 19 Feb 2009, final revision 26 Apr 2009, accepted 17 Jun 2009

\section{Funding}

This study was funded by the Wellcome Trust (grant no. 075712). M.H. and A.S.D. are supported by the South London Maudsley NHS Foundation Trust/Institute of Psychiatry,
King's College London, National Institute of Health Research Specialist Biomedical Research Centre.

\section{Acknowledgements}

We thank the patients and the ward staff.

\section{References}

1 Beauchamp TL, Childress JF. Principles of Biomedical Ethics. Oxford University Press, 2001

2 Owen GS, Freyenhagen F, Richardson G, Hotopf M. Mental capacity and decisional autonomy: an interdisciplinary challenge. Inquiry 2009; 52: 79-107.

3 Owen GS, Szmukler G, Richardson G, David AS, Hayward P, Rucker J, et al. Mental capacity and psychiatric in-patients: implications for the new mental health law in England and Wales. Br J Psychiatry 2009; 195: 257-63.

4 Stone AA. Mental Health and Law: A System in Transition. National Institute of Mental Health, 1975.

5 Stone AA. The right to refuse treatment. Arch Gen Psychiatry 1981; 38 : 358-62

6 Gardner W, Lidz CW, Hoge SK, Monahan J, Eisenberg MM, Bennett NS, et al. Patients' revisions of their beliefs about the need for hospitalization Am J Psychiatry 1999; 156: 1385-91.

7 Kane JM, Quitkin F, Rifkin A, Wegner J, Rosenberg G, Borenstein M. Attitudinal changes of involuntarily committed patients following treatment. Arch Gen Psychiatry 1983; 40: 374-7.

8 Priebe S, Katsakou C, Amos T, Leese M, Morriss R, Rose D, et al. Patients' views and readmissions 1 year after involuntary hospitalisation. Br J Psychiatry 2009; 194: 49-54.

9 Owen G, Richardson G, David A, Szmuker G, Hayward P, Hotopf M. Mental capacity to make decisions on treatment in people admitted to psychiatric hospitals: a cross sectional study. BMJ 2008; 337: 448.

10 World Health Organization. The ICD-10 Classification of Mental and Behavioural Disorders: Clinical Descriptions and Diagnostic Guidelines. WHO, 1992.

11 Grisso T, Appelbaum PS, Hill-Fotouhi C. The MacCAT-T: a clinical tool to assess patients' capacities to make treatment decisions. Psychiatr Serv 1997; 48: 1415-9.

12 Appelbaum PS. Assessment of patient's competence to consent to treatment. N Engl J Med 2007; 357: 1834-40.

13 Cairns R, Maddock C, Buchanan A, David AS, Hayward P, Richardson G, et al. Reliability of mental capacity assessments in psychiatric in-patients. $\mathrm{Br} J$ Psychiatry 2005; 187: 372-8.

14 Okai D, Owen G, McGuire H, Singh S, Churchill R, Hotopf M. Mental capacity in psychiatric patients. Systematic review. Br J Psychiatry 2007; 191: 291-7.

15 Raymont V, Bingley W, Buchanan A, David AS, Hayward P, Wessely S, et al. Prevalence of mental incapacity in medical in-patients and associated risk factors: cross-sectional study. Lancet 2004; 364: 1421-7.

16 Owen GS, David AS, Richardson G, Szmukler G, Hayward P, Hotopf M. Mental capacity, diagnosis and insight. Psychol Med 2008; 22: 1-22.

17 Schwartz $\mathrm{HI}$, Vingiano W, Perez CB. Autonomy and the right to refuse treatment: patients' attitudes after involuntary medication. Hosp Community Psychiatry 1988; 39: 1049-54.

18 Henderson C, Flood C, Leese M, Thornicroft G, Sutherby K, Szmukler G. Effect of joint crisis plans on use of compulsory treatment in psychiatry: single blind randomised controlled trial. BMJ 2004; 329: 136.

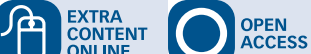

